\title{
Impact of Sickle Cell Disease in Renal Arteries Blood Flow Indices Using Ultrasonography
}

\author{
Mohamed Abdalla Eltahir ${ }^{1,4}$, Mohamed Elfadil Mohamed Gar-elnabi ${ }^{1}$, \\ Mohammed Ahmed Ali Omer ${ }^{1,3}$, Osman Abdelgadir ${ }^{1,2}$, Elsafi Ahmed Abdallah ${ }^{1}$ \\ ${ }^{1}$ College of Medical Radiologic Science, Sudan University of Science \& Technology, Khartoum, Sudan \\ ${ }^{2}$ Sudan Sickle Cell Anemia Center, Obaied, Sudan \\ ${ }^{3}$ Department of Radiologic Technology, College of Applied Medical Science, Qassim University, Buraidah, KSA \\ ${ }^{4}$ Al-Ghad International Colleges for Applied Medical Sciences, Qassim, KSA
}

\section{Email address:}

mohamedsonar@gmail.com (M. A. Eltahir),mohamedelfadilmohamed@gmail.com (M. E. M. Gar-elnabi), alsafi1000@hotmail.com (M. A. A. Omer), ma.omer@qu.edu.sa (O. Abdelgadir), abdelgadirosman@gmail.com (E. A. Abdallah)

\section{To cite this article:}

Mohamed Abdalla Eltahir, Mohamed Elfadil Mohamed Gar-elnabi, Mohammed Ahmed Ali Omer, Osman Abdelgadir, Elsafi Ahmed Abdallah. Impact of Sickle Cell Disease in Renal Arteries Blood Flow Indices Using Ultrasonography. International Journal of Medical Imaging. Vol. 5, No. 2, 2017, pp. 9-13. doi: 10.11648/j.ijmi.20170502.11

Received: February 21, 2017; Accepted: March 3, 2017; Published: March 15, 2017

\begin{abstract}
The aim of this study was to evaluate the impact of sickle cell diseases (SCD) on renal arteries blood flow indices by using of color Doppler ultrasonography (CDU) in addition to relationships with age and body mass index (BMI). The method adapted was an experimental study among a sample consists of 115 SCD patients and 100 as control group. CDU of the main renal and segmental arteries performed among all patients and controls. All the patients were scanned in stable state condition. The results analysis carried out by EXCELL software for the collected variables which revealed that: the patients showed higher resistivity index RI and pulsatility index PI than control subjects (for patients $0.8 \& 1.5$ and $0.7 \& 1.4$ for control group. The significant positive correlation between RI and age $(r=0.194$, and $r=0.061)$ for patients and control group respectively in the right renal artery and as well the RI correlated proportionally with BMI $(r=0.53)$ for patients and $(r=0.05)$ for control group.
\end{abstract}

Keywords: Doppler, Sonography, Pulsatility, Resistivity, Sickle-Cell, Disease

\section{Introduction}

Sickle cell disease (SCD) is among the most common of inherited hemoglobinopathies. The disease has been known since James Herrick, a Chicago cardiologist, first reported it as "peculiar elongated and sickle-shaped red corpuscles in a case of severe anemia" [1]. SCD is a multisystem disorder affecting almost every tissue of the body, however it could induces renal dysfunction and further leading to sickle nephropathy in the later stages. Sickle cell nephropathy is indicated by sickled erythrocytes, with the consequent effects of decreased medullary blood flow, ischemia, microinfarct, and papillary necrosis [2]. Clinical features of the disease result from vasoocclusive consequences of sickled cells more than from the anemia itself. Considering the high prevalence of the disease in certain populations, it is required that renovascular changes be detected at an early stage before irreversible organ damage occurs due to chronic vasculopathy. Irreversible organ damage occurs in at least a third of patients, and thus is the most frequent cause of death beyond early childhood [3, 4]. SCD may result in both renal function disturbances and anatomic alterations. On grayscale sonography evaluation of renal morphologic features in SCD, almost half of the patients with SCD have large kidneys, believed to be a result of increased renal blood volume from the anemia [5]. Also, the kidneys may display normal echogenicity ( $89 \%$ of patients); may be diffusely, mildly echogenic $(5 \%)$; or may exhibit increased medullary echogenicity with normal cortical echogenicity (3\%). Over time, the kidneys may shrink if 
renal failure ensues [6]. However, most of the gray-scale sonography morphologic features are observed in the late course of the disease [4]. SCD also has been noted to induce some biomechanical changes such as intimal hyperplasia, thrombosis, altered vascular reactivity and frank vasospasm. These various mechanisms identify the multifactorial nature of the disease other than just microvascular occlusion by sickled RBC. The mechanisms of vascular intimal hyperplasia and thrombosis in turn are related to the abnormal adhesive and pro-coagulant properties of sickled RBC [7]. Previous literature describes the application of Doppler sonography in the assessment of renal dysfunction in many diseases including renal artery stenosis [8], acutely obstructed kidneys [9], and acute renal failure in determining graft survival in transplanted kidneys and in SCD [10, 11]. However, the trend of this study is focusing on the impacts of SCD in renal arteries blood flow indices as resistive index (an impedance to blood flow and is the ratio of [peak systolic velocity - end diastolic velocity]/Peak systolic velocity) and pulsatility index (is a ratio of [peak systolic velocity - end diastolic velocity]/mean velocity )) $[12,13]$ and to reveal how far (RI) and (PI) would be applicable and utilizable in early diagnosis/predictors of renal impairment among patients with SCD [4].

\section{Methodology}

The study was performed in west of Sudan where SCD has been an endemic disease among the community. The sample consisted of two groups, one group as SCD $(n=$

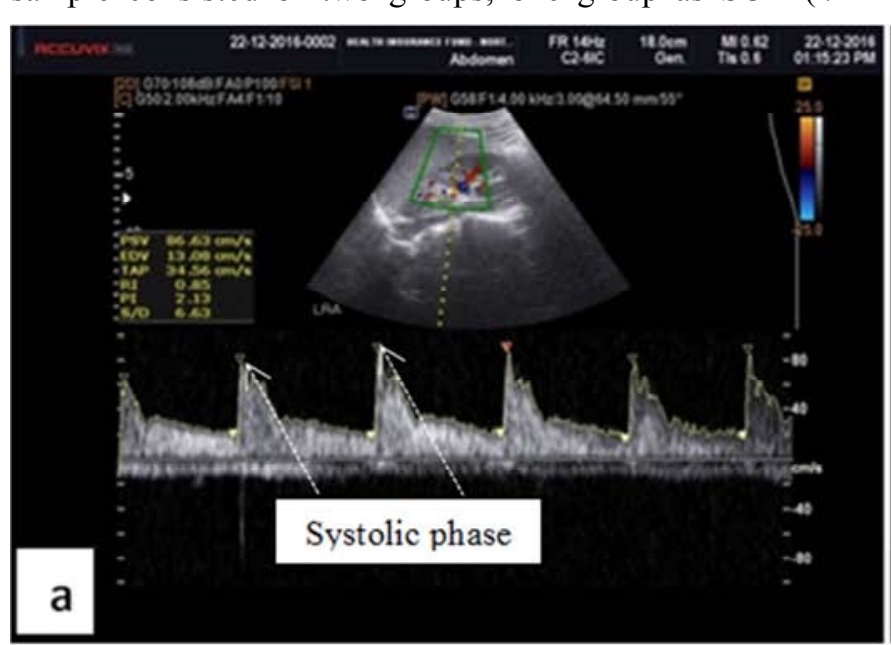

115) referred to hospital with relevant symptoms and signs with age range of 3-21 years. The other group considered as control group $(n=100)$ consisting of randomly selected patients who were routinely attending the ultrasound department for abdominal screening and have been consider to match the patients age to remove the confounding effect of age as well no clinical laboratory and or radiologic evidence of renal disease. The groups have been scanned with two U/S machines (Accuvixxg - AVXGL30-samsungKorea and Mindary DC-N6-China). The probe used was curve linear multi-hertzs probe with utilization of U/S gel to avoid reflection of ultrasound and to maintain a good transmission of U/S beam inside the body. The patients were examined in the supine position: left lateral decubitus for the right kidney and right lateral decubitus for the left kidney. Doppler phenomena has been induced to assess the renal arteries flow indices $(R I, P I)$, for all groups using the non-compression technique based on the method recommended by Krumme et al, [14] as shown in Figure (1) in which the RI of left (a) and right renal arteries (b) were high ( $0.85 \& 0.99$ respectively) while the PI were $(2.13 \&$ 2.14 respectively). Main renal and segmental arteries were scanned using a 2-4 mm Doppler gate. As the average time taken for Doppler assessment of both kidneys in each subject was 20 minutes dependent on the cooperation of the subjects to hold their breath for required intervals, therefore the excluded criteria were related to patients with dyspnea, patients with sickle cell crisis, tachycardia and known hypertensive disease, or who were hypertensive at the time of Doppler induction (systolic blood pressure $\geq 120$; diastolic blood pressure $\geq 80$ ).

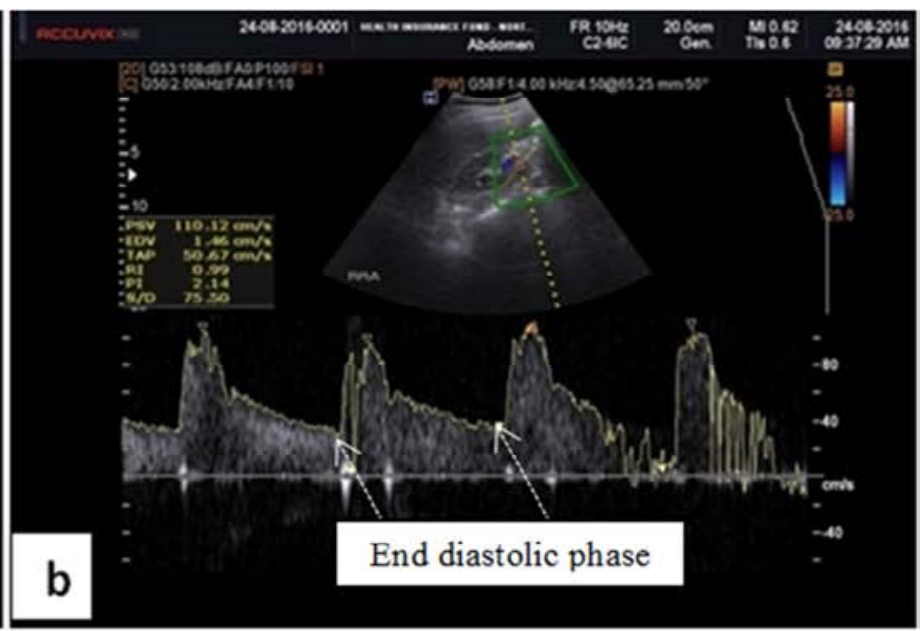

Figure 1. (a) Renal Doppler sonogram shows Lt renal artery with high impedance flow represented by high RI (0.85) \& PI (2.13) and (b) Renal Doppler sonogram shows Rt renal artery with high impedance flow represented by high RI (0.99) \& PI (2.14).

\section{Results}

The following section will highlight the right and left (Rt \& Lt) renal arteries blood flow indices (RI and PI) for SCD patients and control group plotted versus age and BMI. 


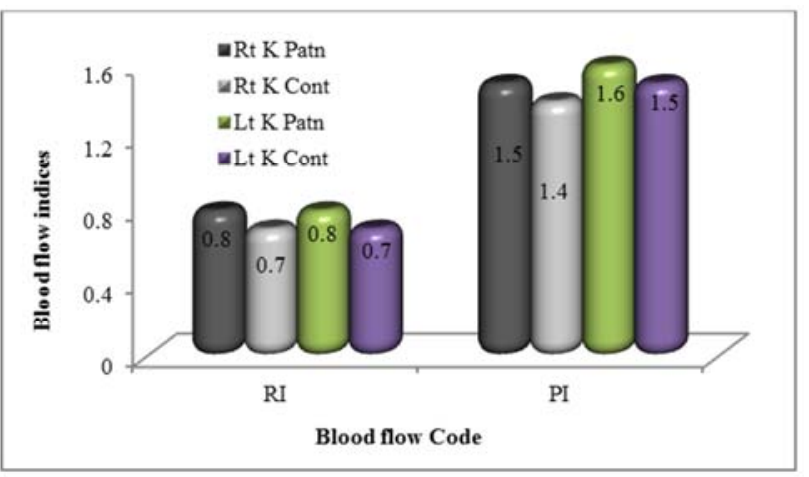

Figure 2. Shows the blood flow indices variation among SCD patient and control group.

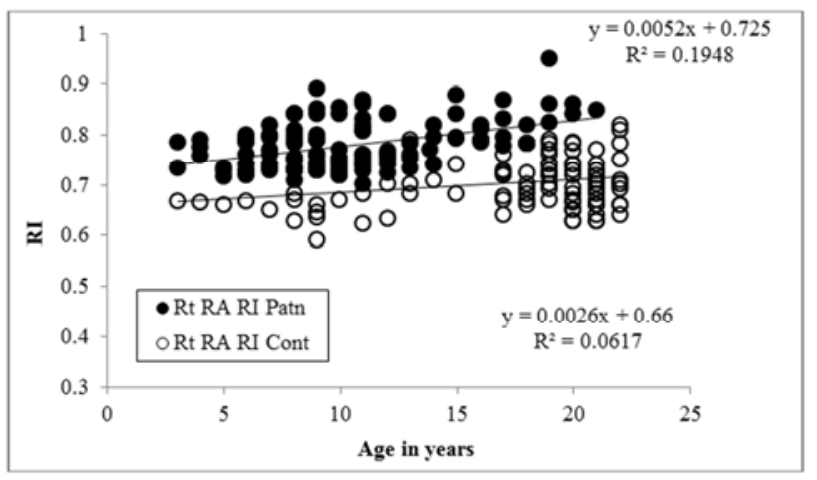

Figure 3. Shows the correlation between the age in years versus Rt renal Artery RI among patient and control group.

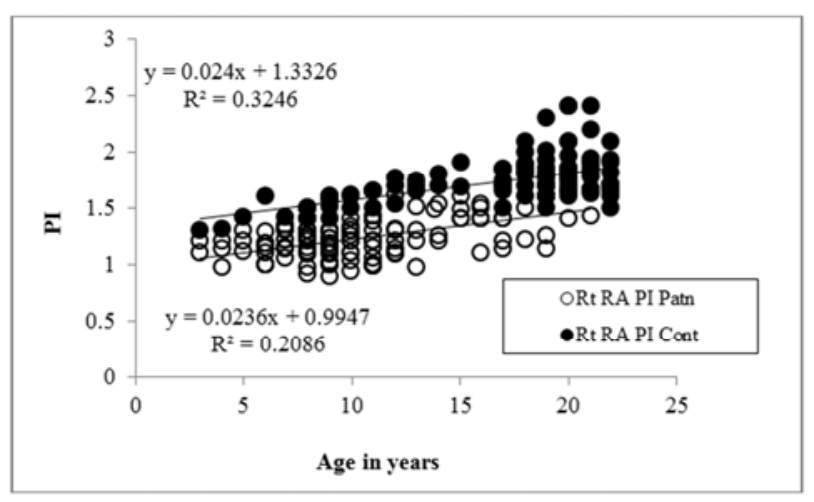

Figure 4. Shows the correlation between the age in years versus Rt renal Artery PI among patient and control group.

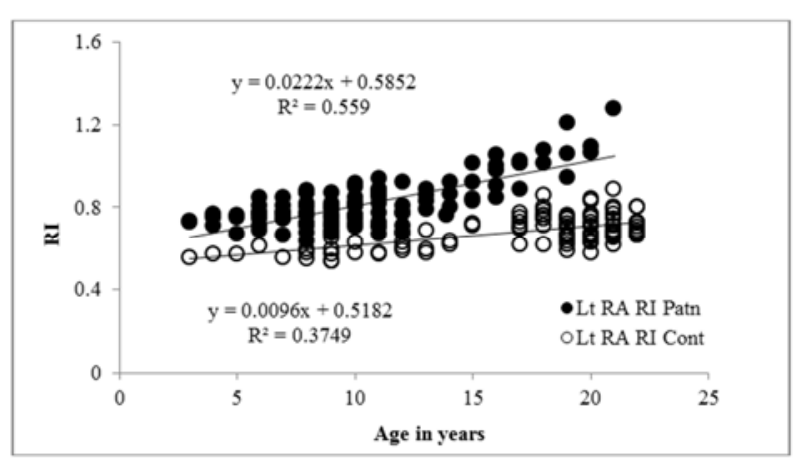

Figure 5. Shows the correlation between the age in years versus Lt renal Artery RI among patient and control group.

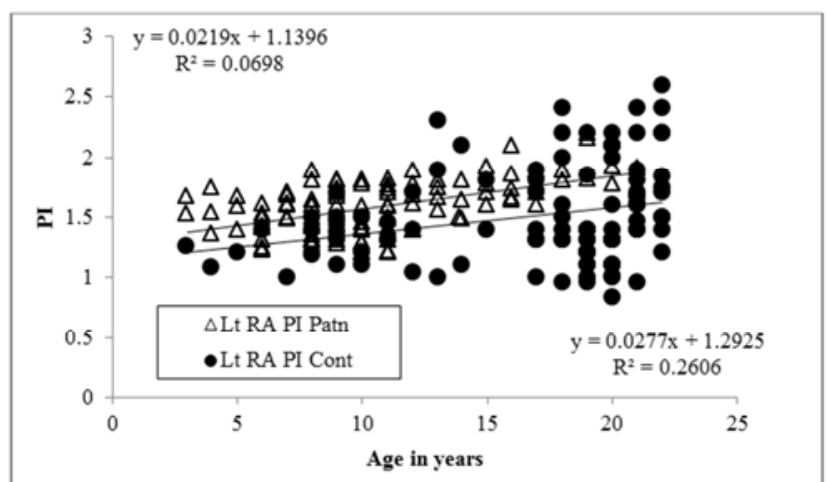

Figure 6. Shows the correlation between the age in years versus Lt renal Artery PI among patient and control group.

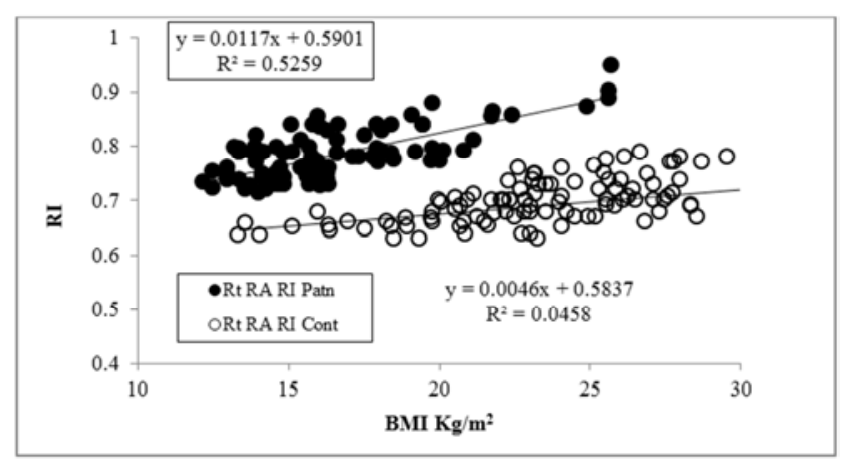

Figure 7. Shows the correlation between the BMI in $\mathrm{Kg} / \mathrm{m}^{2}$ versus Rt renal Artery RI among patient and control group.

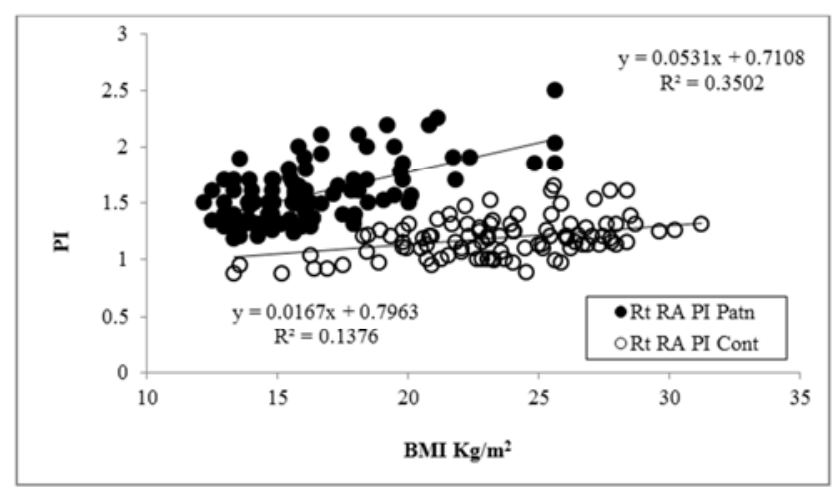

Figure 8. Shows the correlation between the BMI in $\mathrm{Kg} / \mathrm{m}^{2}$ versus Rt renal Artery PI among patient and control group.

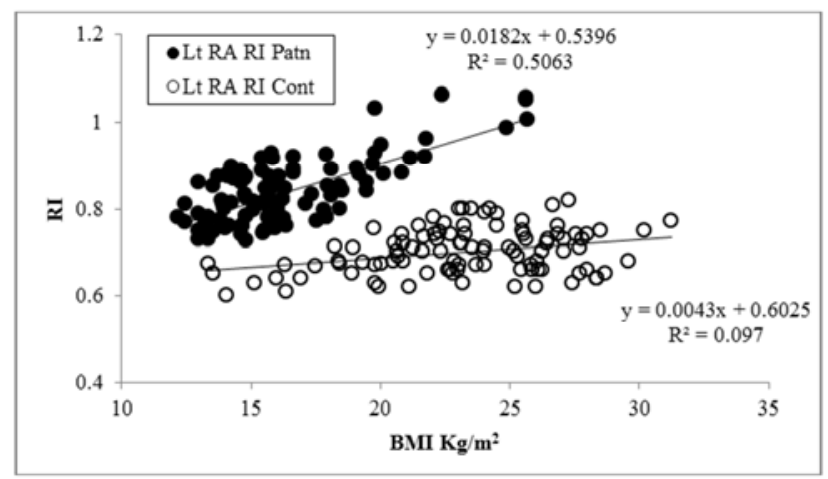

Figure 9. Shows the correlation between the BMI in $\mathrm{Kg} / \mathrm{m}^{2}$ versus Lt renal Artery RI among patient and control group. 


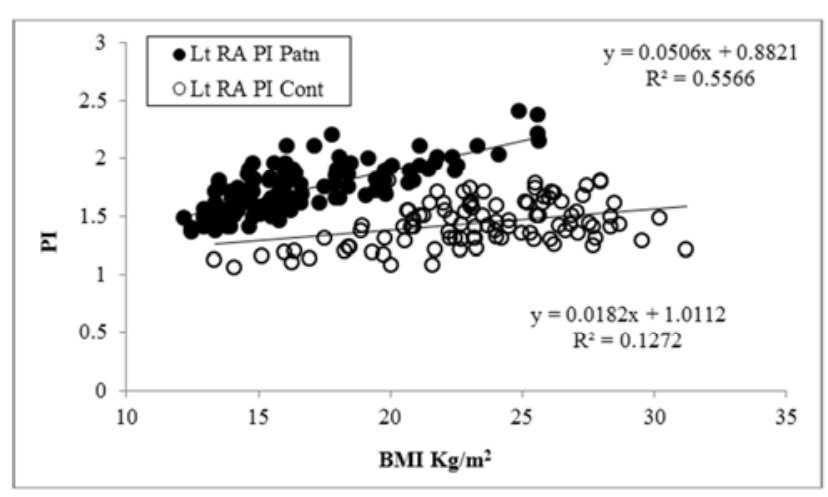

Figure 10. Shows the correlation between the BMI in $\mathrm{Kg} / \mathrm{m}^{2}$ versus Lt renal Artery PI among patient and control group.

\section{Discussion \& Analysis}

The study showed statistically significant elevation in RI and PI (Rt \& Lt kidneys) among SCD patients compared with controls (Figure 2). The right renal artery RI \& PI were $0.8 \pm 0.2 \& 1.5 \pm 0.4$ respectively in patients with linear increment of $0.005 \& 0.023$ year respectively for patients (Figure $2 \& 3)$, while the values of $(0.7 \pm 0.1 \&$ $1.4 \pm 0.4)$ for RI and PI respectively for control group which increased by $0.002 \& 0.024$ /year respectively (Figure $3 \& 4$ ).

The left renal artery RI \& PI showed $0.77 \pm 0.2 \& 1.6 \pm 0.2$ respectively in patients and increased by $0.022 \& 0.021$ /year (Figure $5 \& 6)$. The values of $(0.7 \pm 0.1 \& 1.5 \pm 0.5)$ for RI and PI respectively in control group increased by $0.009 \& 0.027$ annually for RI and PI respectively (Figure $5 \& 6$ ). This results agree with studies conducted by Aikimbaev et al, [15] in which they reported that: there were high renal PIs and RIs in patients with SCD compared with control subjects and as well Taori et al, [16] reported that both RIs and PIs (in the main renal, segmental, and interlobar arteries) were significantly higher in 62 Indian patients with SCD as compared with normal controls. Such high RI and PI among SCD patients ascribed to the increased renal vascular tone resulting from the various vascular occlusive mechanisms occurring in sickle affected kidneys as justified by Robert et al, [7].

The result of this study showed that there is a direct linear relationship between RI and BMI in the Rt renal artery in patients and control group; it was found that RI increased by $0.011 \mathrm{~kg} / \mathrm{m}^{2} \& 0.004 \mathrm{~kg} / \mathrm{m}^{2}$ for patients and control group respectively (Figure 7). Similarly the BMI has direct relationship with PI; where it increased by $0.053 \mathrm{~kg} / \mathrm{m}^{2}$ \& $0.016 \mathrm{~kg} / \mathrm{m}^{2}$ (Figure 8).

The relation between BMI and RI in the Lt renal artery showed that the RI values increased by $0.018 / \mathrm{kg} / \mathrm{m}^{2}$ in patients and $0.004 / \mathrm{kg} / \mathrm{m}^{2}$ in control group (Figure: 9). Also the PI has direct relationship with BMI in the Lt renal artery in patients and healthy one, PI was increased by $0.050 / \mathrm{kg} / \mathrm{m}^{2}$ \& $0.018 / \mathrm{kg} / \mathrm{m}^{2}$ in patients and control group respectively (Figure: 10).

\section{Conclusion}

Since the sickle cell disease has an impact in renal arteries blood flow indices, the worth outcome of this study proved that: Renal Doppler indices as resistivity and pulsatility indices could be used successfully as early sonographic predictors of renovascular changes for Sickle Cell Disease and/or other diseases which would have same or similar impact in the renal arteries blood flow at early stage.

\section{References}

[1] Herrick JB. (2001). Peculiar elongated and sickle-shaped red blood corpuscles in a case of severe anemia. Yale Journal of Biol. Med. 74 (3), 179-184.

[2] Pham PT, Pham PC, Wilkinson AH, Lew SQ. (2000). Renal abnormalities in sickle cell disease. Kidney Int., 57, 1-8.

[3] Powars D, Chan L, Schroeder W. (1990). The variable expression of sickle cell disease is genetically determined. Semin Hematol. 27, 360-376.

[4] Kishor B. Taori, Ritu S. Chaudhary, Vinod Attarde, Suresh Dhakate, Virender Sheorain, Prashant Nimbalkar and Preetam N. Wasnik. (2008). Renal Doppler Indices in Sickle Cell Disease: Early Radiologic Predictors of Renovascular Changes. American Journal of Roentgenology, vol. 191 (1), 239-242. DOI:10.2214/AJR.07.3125

[5] Walker TM, Beardsall K, Thomas PW, Serjeant GR. (1996). Renal length in sickle cell disease: observations from a cohort study. Clin. Nephrol. 46, 384-388.

[6] Harrow BR, Sloane JA, Liebman NC. (1963). Roentgenologic demonstration of renal papillary necrosis in sickle cell trait. N Engl J Med. 268, 969-976.

[7] Robert B. Francis, Jr, and Cage S. Johnson. (1991). Vascular Occlusion in Sickle Cell Disease: Current Concepts and Unanswered Questions. The Journal of the American Society of Hematology, 77 (7), 1405-1414.

[8] Avasthi PS, Voyles WF, Greene ER. (1984). Noninvasive diagnosis of renal artery stenosis by echo-Doppler velocimetry. Kidney Int. 25, 824-829.

[9] Rodgers PM, Bates JA, Irving HC. (1992). Intrarenal Doppler ultrasound studies in normal and acutely obstructed kidneys. Br. J. Radiol. 65, 207-212.

[10] Aikimbaev KS, Oguz M, Guvenc B, Baslamisli F, Kocak R. (1996). Spectral pulsed Doppler sonography of renal vascular resistance in sickle cell disease: clinical implications. Br. J. Radiol. 69, 1125-1129.

[11] Guvenc B, Aikimbaev K, Unsal C, Akgul E, Akgul AE, Binokay F, Besena A. (2005). Renal vascular resistance in sickle cell painful crisis. Int J. Hematol, 82, 127-131.

[12] Mitchell E. Tublin, Ronald O. Bude, Joel F. Platt. (2003). Review: The Resistive Index in Renal Doppler Sonography:Where Do We Stand?. AJR 180,: 885-892.

[13] Rawashdeh YF, Mortensen J, Horlyck A, Olsen KO, Fisker RV, Schroll L \& Frokiaer J. (2000). Resistive Index: an Experimental Study of Normal Range in the Pig. Scand J Urol Nephrol 34: 10-14. 
[14] Krumme B, Hollenbeck M. (2007). Doppler sonography in renal artery stenosis: does the resistive index predict the success of intervention? (editorial) Nephrol Dial Transplant 22, 692-696.

[15] Aikimbaev KS1, Oğuz M, Güvenç B, Başlamişli F, Koçak R. (1996). Spectral pulsed Doppler sonography of renal vascular resistance in sickle cell disease: clinical implications. Br. J.
Radiol. 69(828), 1125-1129. DOI: 10.1259/0007-1285-69828-1125.

[16] Taori KB, Chaudhary RS, Attarde V, Dhakate S, Sheorain V, Nimbalkar P, et al. (2008). Renal Doppler indices in sickle cell disease: early radiologic predictors of renovascular changes. AJR Am J Roentgenol.; 191 (1), 239-242. 